\title{
Placement Cell Android Application and Admin Portal
}

\section{Saiteja N ${ }^{1}$, Shafia Mahedi ${ }^{1}$, Tarun V Gujjar' ${ }^{1}$, Viraj Bhujang Shetty ${ }^{1}$, Suhas S $^{2}$}

'Student, Department of Computer Science and Engineering, The National Institute of Engineering, Mysuru, Karnataka, India

${ }^{2}$ Assistant Professor, Department of Computer Science and Engineering, The National Institute of Engineering, Mysuru, Karnataka, India

Article Info

Volume 7, Issue 3

Page Number: 614-618

Publication Issue :

May-June-2021

\section{Article History}

Accepted : 20 June 2021

Published : 30 June 2021

\section{ABSTRACT}

Training and Placement Cell is an important part of any educational institute, in which most of the work till now is being done manually. The training and placement officer has to inform around thousands of students about every single training and placement related activity. So, to make the placement process easy and effective for the training and placement department as well as the students, an Android application can be developed for students and a website for admin i.e., training and placement department. This website can help the placement officers to provide the details of upcoming companies and their events. And the students can register for all the eligible companies through the android application and view the event of particular company. The android application also provides facility of maintaining details of students along with the placement records of the college. And all the details of the students and the companies are stored in the firebase database. This project will be helpful in faster management of the placement related activities in the college campus.

Keywords: Android Application, Training and Placement Department, Firebase, Angular

\section{INTRODUCTION}

Placement cell is an important part of any college. All the work regarding form filling to scheduling the dates of tests and interviews of various companies can get tedious, not to mention the vast number of students participating, collection of data and maintenance is no easy task. This project is aimed at developing an Android application and an admin portal, reducing the manual work of storing and maintaining of large amount of data.
With the advancement of cloud technology along with android and web applications, it is easier to auto-scale the servers which in turn can lead to more effective ways of hosting and storing data. Android applications come very handy for the students, where applying for any company is few clicks away. An admin panel also acts as a platform for the administrator to simultaneously provide important announcements over remote access. All this is accomplished through an android based application for the students and a web application at the administrator's end with Firebase as database. 


\section{LITERATURE SURVEY}

Sanket R. Brahmankar, Rahul S. Ghule, Shubham K. Chavan, Landge D. Ashish, Pavan D. Borse [1] describe the solution for problem which occurred in existing manual system. The major problem in existing manual system is searching and updating of the student data. The proposed system provides automation in all the processes like registration, update, and searching of the student data. Also, if students are eligible for company, then the student can directly apply for the company by only clicking on apply button. The admin is the master user. Admin has a greater number of priorities than the other users. This paper describes the two steps, the first one is to maintain the list of students and their records and other is to maintaining the company details and based on the company requirements, make the list of students branch wise, which is more complex task.

K. G. Patel, C. K. Patil [2] discuss that online placement system has a very important role in college and to simplify this process by automation is the ultimate goal. The system does all the work regarding collection, modification, updation of student data as well as the companies. With proper authentication of the student, they can apply to specific companies, based on their academic performance. TPO, the admin on the other hand, provides the details of the visiting companies. All the registered students are eligible to participate. The main aim of this system is to reduce manual work and automate process as much as possible.

Chunnu Khawas and Pritam Shah [3] elaborate on how exactly Firebase works with android app. This paper discusses about Firebase that it is a relatively new technology for handling large amount of unstructured data. It is very fast as compared to RDBMS. This paper focuses on the application of
Firebase with Android and aims at familiarizing its concepts, related terminologies, advantages and limitations. The paper also tries to demonstrate some of the features of Firebase by developing an Android app. This paper concludes by saying that using firebase along with android app makes it faster and efficient.

Sourav Mukherjee [4] gives an idea of how important AWS is for businesses to run effectively. He goes on to say that the benefits of AWS in the modern cloud are huge. Data protection, regulatory compliance, quantifiability, flexibility, cost-effectiveness, multiple storages, auto-scaling, access to the data anytime, data-centric encryption, high-performance processing are few benefits of AWS cloud.

\section{SYSTEM ANALYSIS}

\section{A. EXISTING SYSTEM}

- The major problem in existing manual system is searching, sorting and updating of the student data.

- In some cases, students tend to miss the deadlines to fill forms due to very short notices.

- There is huge amount of redundant data due to multiple forms being filled by the same student.

- Chances of giving away wrong information by the students also increases e.g.: wrong email, phone number etc.

- Additional work and thorough checking have to be done to make sure no student violates the criteria of campus drive or ladder policy.

- Students have hard time to keep up with dates and upcoming events.

- Solving each and every query of students regarding placements can be an exhausting task.

\section{B. PROPOSED SYSTEM}

To overcome the drawbacks of existing system the proposed system is developed. The features included in the proposed system are: 
- It provides an easy way for the training and placement officer to upload information and update the details about various companies visiting the campus.

- Students will receive notification about the campus drive beforehand.

- The students need to register themselves and provide the necessary personal and academic details only once, which will be further used to apply to companies whose criteria they match.

- Once any student fits the criteria, they can apply to the particular without much efforts. Thereby, decreasing the chances of redundant and incorrect data.

- Lists of placed and unplaced students along with all the real time statistics can be viewed by the TPO.

- Students can keep up by constantly viewing the announcements tab where all the important information will be posted.

- Students can reach out to the admin by raising tickets, regarding their grievances and queries.

\section{SYSTEM DESIGN}

The architecture system consists of two modules:

1. Android Application for students

2. Admin portal dashboard

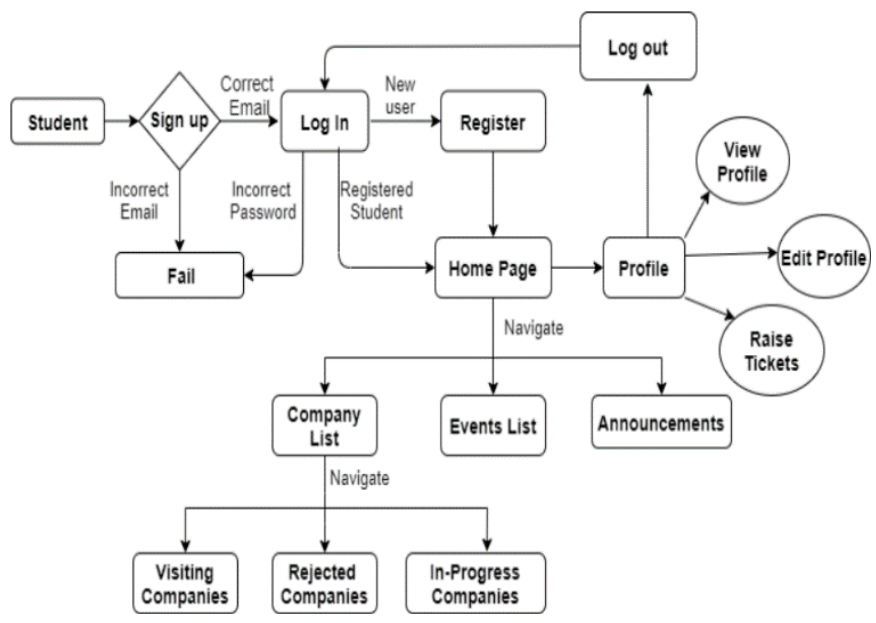

Fig. 1 - Android Application Flow Diagram
Student application is an android application wherein students can register themselves and login to the app to register themselves, edit and view their profile and apply to eligible companies. All the data registered by students will be stored in Firebase database in cloud.

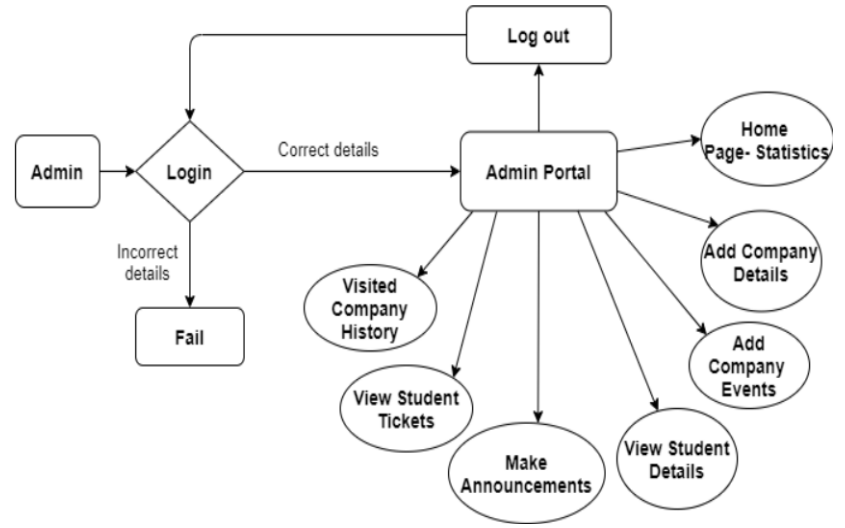

Fig. 2 - Admin Portal Flow Diagram

Admin panel dashboard is a web application where the admin i.e., placement department can view the statistics of the placement activities on various levels. Also, upload company details, events and make any important announcements. The data provided by admin will be directed to firebase and displayed in the android application.

\section{SYSTEM IMPLEMENTATION}

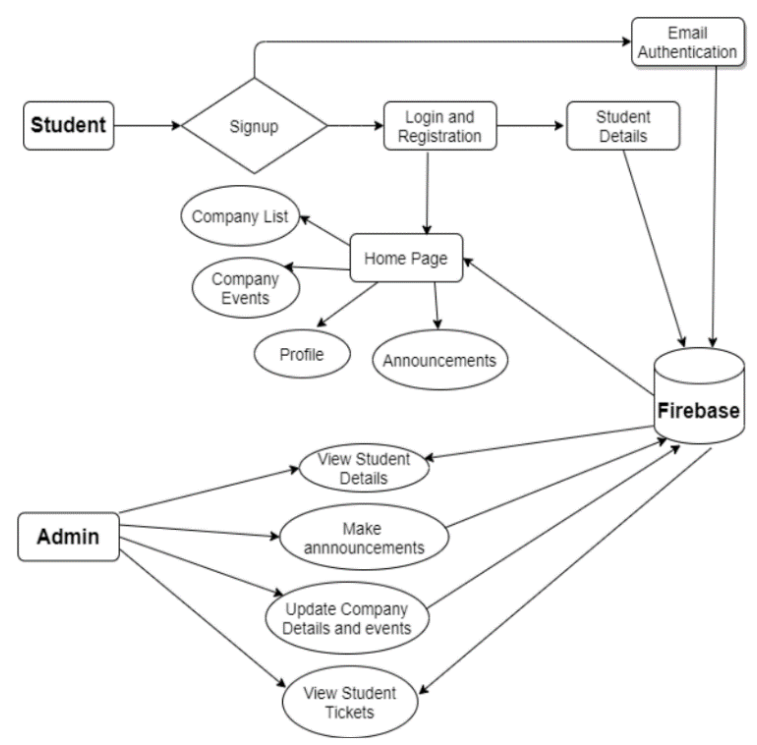

Fig. 3 - System Implementation Diagram 
All the data that has to be stored and retrieved is processed through Firebase database. Here, Firebase acts as the center of all the data storage for both admin and student modules i.e., the web portal and the android application respectively.

Firebase is the NoSQL database which is also cloud hosted and let's us store and sync data in real time. The data is stored in json format. Implicit creation of collections and documents will take place in firebase. Since, Firebase is completely schema-less there is complete freedom over what fields we choose to put in the documents.

There are 2 levels of implementation i.e., android application for students and web portal for admin.

Implementation of android app : A new user has to sign up in the app by providing an appropriate mail id along with password. A verification link will then be sent to their email id, after verifying, their signup will be successful. Then they have to login and register themselves in the app by providing the data asked in the form. After which they enter the HOME page which has the list of all the companies, they are eligible to apply for. They can apply to the company of their choice and while doing so, they can also verify their details and edit resume. IN PROGRESS tab shows the list of companies they have applied to, where they can view the events of that particular company. REJECTED tab shows the companies that they didn't get accepted into. ANNOUNCEMENTS tab is to see the important announcements made by the admin. Users can also view their profile data and statistics in the PROFILE tab. There is an option to raise TICKETS when they have to edit their details or have some queries.

Implementation of admin portal (Web app) : Admin logs in using his credentials. After logging in, admin lands on the home page i.e., the statistics page of the entire placement activities which is shown in real time. The various operations carried out by admin are:

- Add company : This tab corresponds to the "companies" collection in firebase. Whenever admin adds the details, they are automatically updated by creating a document corresponding to that collection which has its own unique id. This goes on to say that each company has corresponding document in the database.

- Company list : After addition of the company, it will be reflected in this tab, where Edit and Delete options are also provided. To create events for a particular company, admin must select the company and fill in the appropriate details. In the database, this "events" subcollection is under the documents of that corresponding company in the main "companies" collection.

- Student list : This corresponds to the "students" collection. This basically lists all the students and their details. The admin has an advantage to sort and search according to his will. The "allow edit" option when enabled, will allow students to make changes to their profile on the app.

- Announcements : Corresponds to "announcements" collection. Each document in this collection will correspond to one announcement. This data will be retrieved and shown in the announcements tab of the android app.

- Student tickets : Corresponds to "tickets" collection. It has all the lists of the tickets raised by the students along with the timestamp. Provisions of sorting and searching are also provided here.

- Visited companies : List of companies that have finished their placement procedure. Along with this data, details of students like applied students, in-progress students, placed students and unplaced students is also provided for that particular company. 


\section{CONCLUSION}

Thus, this paper can be concluded by saying that all the inconsistencies and irregularities in the existing system can be overcome by the proposed system effectively and efficiently. Automation is the key and driving force for the future of technology and customer satisfaction. This paper is an appropriate example of the same. As an extended outcome, the web portal will also be successfully deployed in AWS. When it comes to customer satisfaction this android app will be helpful tremendously and makes their placement experience smoother than ever. While the placement department also doesn't have to struggle to keep up with the large amount of data. Overall, all the placement process is automated.

\section{REFERENCES}

[1]. A Survey on Android App for Training and Placement cell, Sanket R. Brahmankar, Rahul S. Ghule, Shubham K. Chavan, Landge D. Ashish, Pavan D. Borse - Vol-1 Issue-4 2015 -

[2]. http://ijariie.com/AdminUploadPdf/Android_a pp_for_Training_and_Placement_Cell_ijariie13 23_volume_1_14_page_341_345.pdf

[3]. Study of Implementation of Online Placement System, K. G. Patel, C. K. Patil - March 2016 -

[4]. http://www.ijates.com/images/short_pdf/14592 66121_367N.pdf

[5]. Application of Firebase in Android App Development-A Study, Chunnu Khawas, Pritam Shah - June 2018 -

[6]. https://www.researchgate.net/publication/3257 91990_Application_of_Firebase_in_Android_A pp_Development-A_Study

[7]. Benefits of AWS in Modern Cloud, Sourav Mukherjee - March 2019 -

[8]. https://www.researchgate.net/publication/3315 86578_Benefits_of_AWS_in_Modern_Cloud

\section{Cite this article as :}

Saiteja N, Shafia Mahedi, Tarun V Gujjar, Viraj Bhujang Shetty, Suhas S, "Placement Cell Android Application and Admin Portal", International Journal of Scientific Research in Computer Science, Engineering and Information Technology (IJSRCSEIT), ISSN : 2456-3307, Volume 7 Issue 3, pp. 614-618, May-June 2021. Available at doi : https://doi.org/10.32628/CSEIT2173179

Journal URL : https://ijsrcseit.com/CSEIT2173179 